\title{
Genus Lists of Oribatid Mites - A Unique Perspective of Climate Change Indication in Research
}

\author{
V. Gergócs, R. Homoródi and L. Hufnagel \\ Additional information is available at the end of the chapter
}

http://dx.doi.org/10.5772/48545

\section{Introduction}

In most habitats oribatid mites account for the biggest part of microarthropods (e.g. Schenker, 1986, Johnston and Crossley, 2002). They can be found in most terrestrial microhabitats: in soil, leaf litter, moss, underwood, foliage and in aquatic habitats as well (Behan-Pelletier, 1999). They can be found mostly in great species richness and abundance in their habitats (Behan-Pelletier, 1999). They play a significant role in decomposition processes because they fragment the organic matter and influence the biomass and species composition of fungi and bacteria (Wallwork, 1983; Seastedt, 1984; Yoshida and Hijii, 2005). As this group plays a significant role in soil processes, it is necessary to get to know its spatial pattern and the causes of pattern generation, which can be used later for indication (Behan-Pelletier, 1999).

Applicability of Oribatid mites as an indicator group has been emphasized by researchers for several decades. These organisms possess such kind of extraordinary characteristics by which (considered even separately or as a whole) they are able to indicate different changes in their environment. These characteristics have been summarized in several reviews, most thoroughly in the works of Lebrun and van Straalen (1995), Behan-Pelletier (1999) and Gulvik (2007).

Oribatid mites can be found in almost every kind of habitats worldwide: on land, water and most importantly in the layers of soil containing organic materials, but they also conquered several other kind of microhabitats (e. g. lichen, moss, treebark etc.). Apart from the diversity of habitats, their excessive adaptational ability is also shown by great abundance and species richness. In most habitats, they constitute the largest proportion of 
microarthropods. These characteristics mentioned above can be primarily used in the application of coenological methods.

Oribatid mites consume mainly living or dead parts of plants or fungi, however there are some predators and scavengers to be mentioned as exceptions (Behan-Pelletier, 1999). As a consequence, they consume variuos kinds of food, and as such, they participate in numerous ways in the structure of the food web (Lebrun and van Straalen, 1995). Thus they are in strong interaction with their microenvironment (e. g. Ca-storage, heavy metal accumulation (Norton and Behan-Pelletier, 1991, Behan-Pelletier 1999), play an important role in the forming of soil structure and decomposition processes (Behan-Pelletier, 1999). These features can be applied for indicating the effects of chemical or heavy metal pollutions, and disturbances in the succession of decomposition processes (Lebrun and van Straalen, 1995).

The reproduction biology and life cycle of Oribatid mites can be considered extraordinary among arthropods from several aspects. There are some species/populations with sexual and asexual reproduction, and the proportion of species with obligate thelytokous parthenogenesis is very high - around 10\% (Lebrun and van Straalen, 1995). Iteroparity and multiannual life cycle are also quite prevalent among the species, especially in moderate and cold climate zones (Norton, 1994, Luxton, 1981, Behan-Pelletier, 1999). The slow development, low fecundity and long larval stage of Oribatid mites can help indicating long-term disturbances. Their low dispersion ability (Lebrun and van Straalen, 1995) is also quite important, since these mites can hardly flee from sites affected by some kind of stress. Oribatid mites are classified as a "K-selected" group; this can be lead back to their slow metabolism according to Norton (1994). Based on the characteristics listed above, many researchers think that this group is quite promising since it can be used for various indication purposes.

Nowadays there are several methods to describe the natural state of a habitat; the focus is mainly on the measuring of biodiversity. However, uncertainty can arise when measuring biodiversity, as several questions can be raised already as to the explanation of the term, starting from which level it should be considered on (genetic, taxon, ecological diversity), to - if the taxon level has been chosen - the decision on which taxon the focus should be.

The main goal of this study is to set up a comparison scale based on genus-level presenceabsence lists of oribatid mite communities (Acari: Oribatida) of habitats examined on different spatial and temporal scales. The secondary goal - and this time the precondition as well - is to get a reliable picture of the indication strength of the distances to be used, i.e. the information content included.

The indication suitability of the order of oribatid mites for describing the state of their habitat is justified by the special characteristics of the group. Oribatid mites can be found in almost all kinds of habitats: on land and in water; first of all in soil layers containing organic matter as well, however, they have penetrated into different other microhabitats, too (e.g. lichens, moss, bark etc.), which is mainly due to their indeed various food sources (e.g. 
organic debris, fungi, other mites etc.). Besides the diversity of habitats, their high adaptation ability is shown by their enormous abundance and species richness as well. The above characteristics can be mainly used in the case of coenological methods (Lebrun and van Straalen, 1995; Behan-Pelletier, 1999; Gulvik, 2007; Gergócs and Hufnagel, 2009).

The choice of the genus level can be explained by different aspects. In the analysis by Caruso and Migliorini (2006) it was shown that there were not any significant changes in data examining anthropogenic disturbance on oribatid mites when switching from species level to genus level. Our study has a similar goal as we would like to show potential habitat changes with our method. Podani (1989) had a similar observation in case of plants, according to which switching to genus level does not mean a significant change when comparing the examined habitats. Osler and Beattie (1999) carried out a meta-analysis similar to ours, which confirmed their expectation that taxonomic levels above species are more suitable for comparing habitats. This research showed further that habitats can be chosen on family level in case of oribatid mites, therefore our study covers besides the genus level the family level as well. There were also some other arguments for our decision, namely that the number of databases used could be considerably extended in this way, in addition, taxonomical processing became faster and more reliable in our field studies as well. Genus-level identification of oribatid mites is solved on the basis of the work by Balogh and Balogh (1992) on a global scale, too. However, species-level identification is only possible in case of some zoogeographical regions and only some taxa on a global scale as the related literature is not properly synthesized yet (e.g. Balogh and Mahunka, 1983; Olsanowski, 1996).

\section{Review of literature - Suitability of oribatid mites as indicators}

Research into oribatid mites goes back to the 1880s, the work of A. Berlese, who invented the Berlese funnel and made it possible to extract and examine soil mesofauna more precisely. His lifework was carried on by several renowned taxonomists, such as Grandjean, Hammer, Beck, Aoki, Wallwork, Engelbrecht, Corpus-Raros, Lee, Pérez-Inigo, Baggio, Bhattacharia and Haq (Balogh et al., 2008) with taxonomical descriptions of oribatid mites covering the bigger part of terrestrial habitats. Due to the above researches, nowadays it has become possible to examine oribatid mites from different indication aspects on community level.

One part of the studies on indication possibilities compares natural habitats. In these studies the goal is to reveal spatial and temporal pattern generation characteristics of habitats. Temporal change is examined in few studies (Irmler, 2006) and in case of spatial examinations different approaches are used: on substrate level (e.g. Fagan et al., 2006; Lindo and Winchster, 2006), examining altitudinal zonation of mountains (Migliorini and Bernini, 1999; Reynolds et al., 2003; Jing et al., 2005) and only seldom on the level of habitat types (Balogh et al., 2008). These studies do not always yield consistent results, however, the examinations prove that patterns exist. 


\subsection{Comparison of natural habitats}

These examinations try to explore what properties of habitats play a role in pattern generation, among which spatial and temporal changes can be distinguished. Observations on seasonality have not yielded considerable results (Reynolds et al., 2003, Noti et al., 1996, Badejo et al., 2002, Moldenke and Thies, 1996). Habitats and sampling frequencies are quite different and hardly comparable. Currently we do not possess any satisfying results on seasonal dynamics. A number of studies (Reynolds et al., 2003) surveying temporal changes measured the total abundance of the community. Measuring the changes in the number of individuals of larger groups does not mean thorough examination. It is worth to survey the temporal structures of the entire community on such places where seasons are well discernible. One of the most important studies has been made by Irmler (2006), who studied the seasonal changes of an Oribatid community living in the OL and OF layer of a beech forest. It was found that only the annual mean temperature had significant effect on the structure of the community. The study yielded more results when Irmler surveyed the seasonal dynamics of individual species. Mainly the amount of precipitation affected the abundance of certain species, but some species had been affected more significantly by temperature (primarily by the mean temperature in January). The significance of specieslevel examination was confirmed by the fact that certain species reacted differently on the surveyed parameters.

Spatial comparisons applied different scales; part of them compared soil and foliage of forests. These studies revealed that Oribatids of the soil showed greater $\alpha$-diversity and species richness, but $\beta$-diversity proved to be greater in the foliage, which means difference among samples taken from individual trees has been greater than that of the samples collected from the soil (Lindo and Winchster, 2006, Fagan et al., 2006).

Comparison of elevations above sea level attracted great attention: primarily the abundance and species richness of Oribatids have been studied in zones of different altitudes. However, obtained data are not concordant: according to Migliorini and Bernini, (1999) and Fagan et al., (2006) the abundance of Oribatids decreased with altitude, but Jing et al., (2005) and Reynolds et al., (2003) observed an opposing tendency. Fagan et al., (2006) pointed out a decrease in species richness, Migliorini and Bernini, (1999) observed a growth in diversity as a function of increasing altitude. It has to be mentioned by these contradictory results that altitudes of sampling and habitats are hardly comparable, and even if they were, this would not guarantee consistent results. This has been pointed out by Andrew et al., (2003) in an extended series of studies conducted on different altitudes in Australia and New Zealand.

Beside altitude, vegetation also changes greatly when progressing upwards on a hill. Studies mentioned above did not lay an emphasis on vegetation. The work of Balogh et al.(2008) however demonstrates altitude as a difference in the type of vegetation: rainforest, moss forest and paramo. Samples were taken from the mountains of Brazil, Costa-Rica and NewGuinea. This work showed that the structure of Oribatid mite communities was primarily determined by the type of vegetation and not by the distance of several thousand 
kilometres, which means that climate and ecological conditions have stronger effects than zoogeographical connections (Balogh et al., 2008).

\subsection{Abundance, species richness and diversity}

Studies examining Oribatid communities almost always measure which Oribatid species and in what quantity are present in samples taken from the given area. Species composition, abundance, total abundance, species richness, diversity and the uniformity of the community can be calculated from these data. In most cases, changes in the communities are examined using these variables.

When given the same climate, abundance, species richness and diversity of the Oribatids are greater in natural areas (forest or habitats not strongly affected by human activity) than in areas affected by agriculture (e.g. plant production or animal husbandry) or forestry (e.g. clear-felling, burning etc.) (Bedano et al., 2006, Osler et al., 2006, Cole(et al 2008, Olejniczak 2004, Arroyo and Iturrondobeitia, 2006, Migliorini et al., 2003, Altesor et al., 2006). The observation of Bedano et al. (2006) can be mentioned as an exception: it was found that the abundance of pastures was higher than that of natural forests.

Decrease in abundance can be caused by hard frost (Sulkava and Huhta, 2003) and serious heavy metal pollution (Seniczak et al., 1995). According to Osler et al. (2006), mainly the number of individuals is lower in the initial state of succession. Decrease in abundance could be pointed out primarily as a result of water deficiency ( $\mathrm{O}^{\prime}$ Lear and Blair, 1999, Lindberg et al., 2002), but contradictory results had been also obtained (O'Lear and Blair, 1999, Melamud et al., 2007). Lindberg and Bengtsson, (2006) showed that community regeneration following drought can not be satisfactorily measured by the sole application of total abundance. Decrease in the abundance of Oribatids can also be caused by ash treatment of sour, acidic soils (Liiri et al., 2002). In Japanese coniferous forests it has been shown that the abundance of Oribatids was greater in mixed litter (litter of several tree species) than in litters consisting of only one tree species (Kaneko and Salamanca, 1999). Kovács et al., (2001) explored positive correlation between the nutrient content of the soil and abundance, but it was contradicted by several other studies (e.g. Osler and Murphy, 2005).

Removal of winter snow cover lead to a decrease in species richness, since the mesofauna of the soil has been exposed to greater fluctuation of temperature (Sulkava and Huhta, 2003). Response of species to heavy metal pollution varied greatly, sometimes even moderate pollution resulted in the highest species richness (Skubala and Kafel 2004). Drought generally decreased species richness (Tsiafouli et al., 2005), but there were several examples for growth as well (Melamud et al., 2007). Ash treatment lowered abundance and also species richness (Liiri et al., 2002). In mixed litter, both species richness and abundance were higher (Kaneko and Salamanca, 1999). Fagan et al., (2006) found in Canadian coniferous forests that species richness of Oribatids in the soil had been greater when comparing Oribatid communities of the foliage and soil. 
Diversity data can be found primarily in agricultural and forestry studies. It has been pointed out that irrigation (enhancing the moisture content of the soil) increased the diversity of Oribatid communities, because it raised the individual numbers of rare species (Tsiafouli et al., 2005). Drought had a detrimental effect on diversity (Lindberg et al., 2002). Studies of Taylor and Wolters (2005) pointed out that Oribatid diversity had been greater in a more decomposed beech litter than in fresh litter. Seniczak et al., (2006) concluded that Oribatid diversity can be increased by increasing the number of ponds of forest habitats, since this means more ecotones and leads to the presence of such kind of species which prefer humid habitats and are normally absent from forest habitats. Age of temperate deciduous forests did not affect diversity (Erdman et al., 2006). Growth in the diversity of tree species did not increase the diversity of Oribatids living in the soil of these forests (Kaneko et al, 2005. However, growing diversity of the litter not only increased abundance and species richness, but diversity as well (Coleman 2008). (Table 1.)

\begin{tabular}{c|c|c}
\hline abundance & species richness & diversity \\
\hline artificial disturbance $\downarrow$ & artificial disturbance $\downarrow$ & artificial disturbance $\downarrow$ \\
\hline hard frost $\downarrow$ & snow cover removal $\downarrow$ & irrigation $\uparrow$ \\
\hline drought $\downarrow$ & drought $\downarrow$ & drought $\downarrow$ \\
\hline early stage of succession $\downarrow$ & ash $\downarrow$ & number of ecotones $\uparrow$ \\
\hline diverse litter mix $\uparrow$ & diverse litter mix $\uparrow$ & diverse litter mix $\uparrow$ \\
\hline ash treatment $\downarrow$ & & soil > foliage \\
\hline heavy metal pollution $\downarrow$ & & \\
\hline organic mater content $\uparrow$ & & \\
\hline
\end{tabular}

Table 1. Strongly abridged summary of information from studies on characteristics of Oribatid communities. $(\uparrow=$ increases or greater; $\downarrow=$ decreases or lower $)$

With the overview of available studies, it can be clearly explored how various characteristics of Oribatid communities are modified due to changes in moisture, temperature, heavy metal concentration, organic matter content and level of disturbance. The most important question concerning the application of Oribatids as indicators is to clarify what kind of information content does natural Oribatid coenological patterns possess from the aspect of bioindication. Most of the variables listed above can be directly measured, since rapid methods are available to quantify temperature, heavy metal content etc. of the soil. Responses of Oribatids are worth to study in a more complex approach. Even now we have an expansive (but far from satisfactory) knowledge on how communities change due to modifications of different factors. These pieces of information necessitate the elaboration of such methods which render Oribatid communities suitable for the task to prognosticate what extent the given site can be considered near-natural or degraded, based on the Oribatid composition of a single sample taken from the given area. Raising further questions will be possible only after obtaining the answer for this problem. However, answering this problem needs extensive and coordinated work: approriate reference sites need to be appointed to clarify the concept of naturality, sampling and processing methods need to be standardized 
internationally - in conformity with the given environmental conditions - and the field of data processing methods also has to be developed. Definition and testing of Oribatid-based (or mesofauna-based in a broader sense) coenological indicators are also undoubtedly needed. The usefulness of Oribatid characteristics summarized in the introduction had been recognized long ago, now it is time to conduct research in a way that enables to explore and exploit the actual advantages Oribatid mites provide.

\section{Similarities of genus lists on different scales}

By setting up the spatial and temporal scales, we expected that the order based on the genus lists later should correspond to the real spatial and temporal scales, either the farther and qualitatively the more different habitats our lists originate from, the greater difference there should be among similarities inside the given categories. However, if data originate from the same site, the difference among the examined samples should be greater in case of the lists which are farther in time from each other.

The main goals of the present study are the following:

1. Developing a spatial and temporal scales reference based on the genus -level taxon lists with the help of similarity functions.

2. Examining the degree of distances in the similarity order used for indication.

\subsection{Examination of the suitability of the genus level}

Our analysis related to the notion that the genus level does not mean great data loss compared to the species level was carried out based on the databases by Marie Hammer. The work of Hammer was chosen due to the homogeneity and very extensive geographical cover of the databases. The series originate from two different sites of six different countries accordingly (Hammer, 1952, 1958, 1961, 1962, 1966, 1972). Besides the species and genus level the family level was analyzed as well, according to the taxonomical classification in the work by Balogh and Balogh (1992).

For our examination comparisons on genus level are sufficient as switching from species level to genus level did not cause a significant change regarding the distance and position of habitats according to the results of the ordinations. On family level inconsistency is caused by losing information. Using species-level data would be impractical due to taxonomical uncertainty on the one hand and lack of reliable databases on the other hand, and thirdly, due to unjustified increase in distance caused by genera with large number of species.

\subsection{Categories of the genus lists}

In order to be able to determine to which spatial and temporal distance the oribatid mite genus lists of two samples/sites examined by us correspond, different categories had to be defined. The categories were set up considering which combination of the given spatial and temporal scales the examined genus list pairs originate from. Regarding the time (Ti), 
differences between 0, 2, 12, 24 and 52 weeks and due to a study (Melamud et al., 2006(2007) were able to consider six years i.e. 312 weeks, too. In space the smallest distinguishable unit was the different substrate $(\mathrm{S})$, then the different types of habitats/sites $(\mathrm{H})$, the different topographicums (T) follow, and finally the largest unit was the zoogeographic kingdom (K). Substrate is the lowest vegetation level such as soil, förna, leaf litter, moss, bark etc. Site means habitat types such as rainforest, mossy forest, páramo etc. Topographicum is practically a country such as Papua New Guinea or Chile. When differentiating between zoogeographic kingdoms, six kingdoms found in the work by Balogh and Balogh (1992) were considered: Holarktis, Neotropis, Aethiopis, Orientalis, Australis (there Notogea) and Archinotis (there Antarctis), which is the modified version of Müller's system (1980).

\subsection{Sources of the genus lists}

Genus lists of the different categories were collected from various sources. The first category means the similarity between genus lists of samples collected from the same zoogeographic kingdom (SaK), the same topographicum $(\mathrm{SaT})$, the same type of site $(\mathrm{SaH})$, the same substrate (SaS) and at the same time (Ti-0) (SaK/SaT/SaH/SaS/Ti-0). One part of these genus lists was obtained from our own research. From the soil of a dry oak forest in Törökbálint (Hungary), 9×300 $\mathrm{cm}^{3}$ förna sample was collected and the mesofauna was extracted from it, the oribatid mites were sorted out and identified to genus level according to the works by Balogh (1965); Balogh and Balogh (1972, 1992); Balogh and Mahunka (1980, 1983) and Olsanowski (1996). Further data for this category were collected by studying the scientific legacy of the late János Balogh, member of the Hungarian Academy of Sciences.

Data for the following four categories were also collected from our research. Samples were collected in 2005 and 2006 in a given quadrat of $100 \mathrm{~m}^{2}$ in a dry oak forest in Törökbálint, Hungary (N 47 $25^{\prime} 38^{\prime \prime}$ E $18^{\circ} 54^{\prime} 16^{\prime \prime}$ ) and they were surveyed every two weeks. Every time samples were obtained from three types of substrates: from $500 \mathrm{~cm}^{3}$ leaf litter, $300 \mathrm{~cm}^{3}$ förna (from under the leaf litter) and $0.5 \mathrm{dm}^{2}$ hypnum moss (Hypnum cupressiforme) living on tree trunks. Oribatid mites were extracted with the help of a Berlese-Tullgren funnel (Coleman et al., 2004) and identified on genus level. This examination made it possible to set up categories on pattern levels meaning a distance of two, 12, 24 and 52 weeks, in which substrate $(\mathrm{S})$, site $(\mathrm{H})$, topographicum $(\mathrm{T})$ and zoogeographic kingdom $(\mathrm{K})$ were the same (Sa). Abbreviations of these categories are: SaK/SaT/SaH/SaS/Ti-2, SaK/SaT/SaH/SaS/Ti-12, $\mathrm{SaK} / \mathrm{SaT} / \mathrm{SaH} / \mathrm{SaS} / \mathrm{Ti}-24$ and SaK/SaT/SaH/SaS/Ti-52. A study by Melamud et al. (2007) was implied as well, in which samples were collected at different altitudes of Mount Carmel in Israel from the same sites with a difference of six years (312 weeks) (SaK/SaT/SaH/SaS/Ti-312).

Regarding spatial differences, the smallest change in scale is the difference in the substrate: SaK/SaT/SaH/DS/Ti-0, i.e. the substrate is different (D), however, there is no change in time (Ti-0). Genus lists belonging to this category originate from our own database and the above mentioned manuscripts by Balogh. Databases of three further studies were used as well (Behan-Pelletier and Winchester, 1998; Fagan et al., 2006; Lindo and Winchester, 2006). 
In case of the following seven categories, only spatial scales "above" substrate change, substrate and time are not differentiated any more so they are marked " $\mathrm{X}$ ". Abbreviation of the same type of sites which can be found in the same zoogeographic kingdom and in the same topography is SaK/SaT/SaH/XS/Ti-X. Genus lists belonging to this category were obtained from the manuscripts by János Balogh, the study by Migliorini et al., (2005) and the studies by Hammer $(1958,1961,1962,1966)$. Abbreviation of the category of different sites is $\mathrm{SaK} / \mathrm{SaT} / \mathrm{DH} / \mathrm{XS} / \mathrm{Ti}-\mathrm{X}$. Sources of the series belonging to this category are: studies by Noti et al. (1996); Migliorini et al. (2002); Osler and Murphy (2005); Skubala and Gulvik (2005); Arroyo and Iturrondobeitia (2006); Osler et al. (2006), manuscripts by János Balogh, published series by János Balogh (Balogh et al., 2008) and studies by Hammer (1958, 1961, 1962, 1966). A series belonging here originates from samples collected by Levente Hufnagel in Australia (2006, Australia: QLD, Cairns)

In case of genus lists originating from different topographicums, we considered the point if they originate from the same (SaK/DT/SaH/XS/Ti-X) or different sites (SaK/DT/DH/XS/Ti-X) and if the two topographicums can be found in the same or different zoogeographic kingdoms (DK/DT/SaH/XS/Ti-X, DK/DT/DH/XS/Ti-X). These series come from studies by János Balogh and Marie Hammer.

In the last category only the zoogeographic kingdom can be interpreted as the complete genus lists of the six zoogeographic kingdoms were compared in it according to the work by Balogh and Balogh (1992) (DK/XT/XH/XS/Ti-X).

\subsection{Data processing methods}

The lists created from the Hammer-databases were analysed with Ochiai, Jaccard and Sørensen distance functions and non-metric ordination using the software Syn-tax 2000 (Podani, 2001).

From the other databases we did not consider all possible list combinations which fit the category, only the ones having at least nine genera. After our complete genus list database was set up, the number of genera of the two lists and the number of the common genera were determined considering the genus list pairs in each category. As we had only presenceabsence data and the value " $\mathrm{d}$ " of the contingency table was not considered in case of the genus list pairs, the Ochiai and Jaccard functions were used as distance functions (Podani, 1997). The similarity data of each category was calculated from the means of the values of the distance functions for the genus list pairs.

As our data were not always independent within a category, it was determined with a complex method to what extent the means of the categories differ from each other. We had several distance function values within each category as we. We had 106 genus list pairs within one category on average. From among the distance function values of each category fifteen values were chosen randomly with the help of a random number generator in the Excel software. It was carried out ten times in case of each category. In this way we got 10 series containing 15 values for each category. Series of the data table containing $10 \times 15$ values 
in case of each of the 14 categories were now independent and since normal distribution could not be observed within each category, the data were analysed with the Kruskal-Wallis statistical test. Each of the 14 series were analysed with the Mann-Whitney post hoc test as well, so we got ten tables containing $14 \times 14$ post hoc test results. One table was made out of these ten, which shows $95 \%$ confidence interval of the appropriate values of the ten tables. Based on this we were able to decide which categories differ from each other significantly. These statistical tests were carried out using PAST software (Hammer et al., 2001).

\subsection{Order of the genus list categories}

As we got nearly the same results using both distance functions (Ochiai and Jaccard), only the results calculated with the help of the Ochiai function are discussed further. Fig. 2 displays intervals with defined standard error around the Ochiai distance means in case of each category.

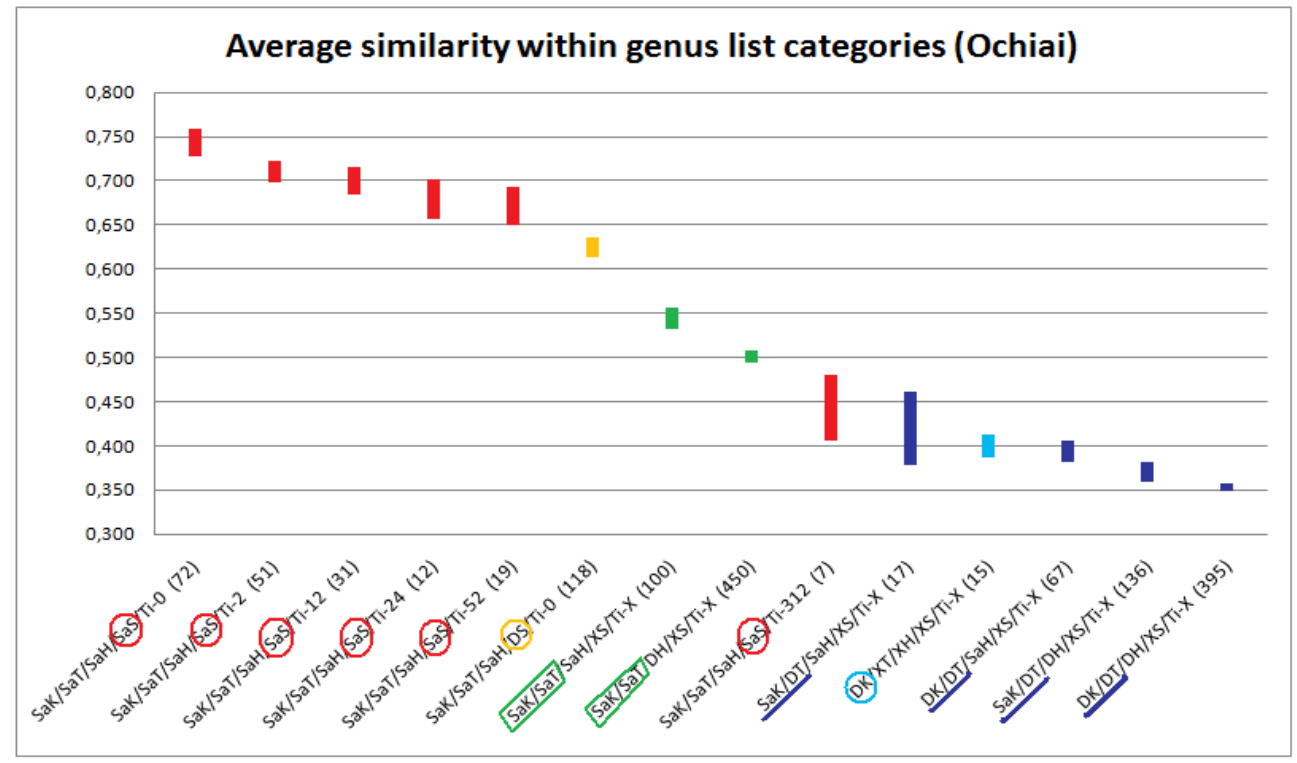

Figure 1. Average distance within genus list categories using Ochiai function. Next to the category codes, the number of genus list pairs used for calculating the average can be seen in brackets. Remarkable code parts are highlighted

In Fig. 2 it can be seen that the largest similarity between samples can be observed in the category where all criteria are the same (SaK/SaT/SaH/SaS/Ti-0) i.e. where the samples were collected at the same time and from the same substrates. Similarities of genus lists originating from different time but the same substrates are the next: first the two-weekdifference, then the 12-, 24- and finally the 52-week-difference. Among comparisons on sample level the last one marked with yellow colour is the similarity of genus lists originating from different types of substrates. 
As expected, within the same topographicum there is larger similarity between genus lists coming from the same type of sites than between those coming from different sites. This is where the sample series meaning six-year-difference (SaK/SaT/SaH/SaS/Ti-312) turn up. This considerable difference is amazing within one given habitat.

Among the last five there are the four categories in which the difference between lists originating from different topographicums (DT) is measured. Regarding the order of these four categories it is remarkable that the same type of site shows larger similarity than different sites, irrespective of the fact whether the different topographicums are in the same or different zoogeographic kingdoms. This corresponds with the results of a former study conducted with other methods (Balogh et al., 2008). The category DK/XT/XH/XS/Ti-X fits in the above mentioned categories in the order. Using the Jaccard distance function this is the only category position that changes places with the category DK/DT/SaH/XS/Ti-X.

The order set up with the help of genus lists based on the complete database met our expectations, so it can be definitely an appropriate reference in indication researches.

The significance of distances between genus list categories was tested by a Mann-Whitney tests. Our first remarkable result is that the average distances between genus lists originating from the same substrate but from different dates within a year does not differ from each other significantly. According to our former assumptions time difference could have been detected regarding a one-year-difference, however, it could not be detected from the substrates of the temperate dry oak forest studied. Consequently, if genus lists of the complete habitat type were examined with time lags less than a year, no change could be detected on site level, either. Irmler (2006) had a similar result on species level in a long-term European study.

The difference between oribatid mite communities originating from different substrates (DS/Ti-0) can be significantly larger in case of certain distance functions than the difference between communities coming from the same type of substrate (SaS/Ti-0). Besides, there is no large difference between samples collected within a year from a given type of substrate. It follows from these two statements that if genus lists originate from different types of substrates, there is larger difference between them than if samples are collected within a year from the same type of substrate. Consequently, the quality of substrate in a given habitat type is a more important factor in the composition of the oribatid mite community than time changes within a year.

Similarity between oribatid mite genus lists of the same types of sites (SaK/SaT/SaH/XS/Ti-0) differs significantly from the similarity between genus lists originating from the same type of substrate $(\mathrm{SaK} / \mathrm{SaT} / \mathrm{SaH} / \mathrm{SaS})$ if samples were collected with a time lag of maximum 24 weeks in the latter case. At the same time, the distance between genus lists coming from different types of substrates is similar to the distance between oribatid mite genus lists of the same or different habitats in a given topographicum, i.e. the type of substrates plays a similarly important role in the quality of the oribatid mite community as habitat types in a given topographicum. 
The distance between genus lists originating from the same or different types of substrate is much smaller than the distance between genus lists of different topographicums (XK/DT/...), independently of the fact if sites in the same or different zoogeographic kingdoms are compared. More remarkable is the fact that the similarity of genus lists coming from the same sites in the same topographicums does not differ significantly from the similarity of genus lists originating from the same sites in different topographicums. It means that oribatid mite communities of the same types of habitats resemble each other nearly in the same way no matter if they originate from the same or different topographicums.

\section{Seasonal change of oribatid mite communities (case study)}

Several researches have already been done to detect the pattern and composition of oribatid mite communities and their exact causes. However, it is hidden to date by which mechanisms the structure and functioning of the individual communities are affected.

Climatic factors belong to the most determinant ones. The above statement is reflected by the number of researches as well, because most of the studies on oribatid mite communities investigate how the communities react to the meteorological factors changing naturally or artificially, especially to temperature and the amount of precipitation (Gergócs and Hufnagel, 2009). First it is worth investigating the effect of the natural changes of the climatic factors, and the most appropriate way to do this is to study the seasonal changes of the communities. The mistake in most of these studies is that the research on seasonality is conducted over a maximum of a year (e.g. Schenker, 1984), so it cannot be determined whether the observed phenomena occur similarly each year. The most significant research on this topic was conducted by Irmler (2006) in a beech forest in Germany. He investigated monthly changes of ground-dwelling oribatid mite communities over a seven-year period and found that there are no important changes among the communities.

Our research is similar to his one, however, it differs as well because we collected samples every two weeks and not once a month, and we investigated not one but three microhabitats over a one and a half year period in an oak forest in Hungary.

The other difference is that data on oribatid mites were recorded on genus level and not on species level. The decision on the genus level can be justified by several factors. The analysis of Caruso and Migliorini (2006) showed that there were not any important changes in the data when studying human disturbance on oribatid mites and changing from species level to genus level. Podani (1989) found a similar result in case of plants, namely, changing to genus level does not mean a significant difference when comparing the studied habitats. Osler and Beattie (1999), Hammer and Wallwork (1979) and Norton et al. (1993) concluded according to their studies that the many widespread genera and families indicate that the similarity between oribatid mite communities should be studied above species level. In their meta-analyses their assumption was confirmed that taxonomical levels above the species level are more suitable to compare habitats. According to this we also compared the data series recorded with time difference on genus level. 
The aim of our study was to explore which seasonal changes occur in oribatid mite communities living in three types of microhabitats in an oak forest and what role the most important climatic factors that is the amount of precipitation and temperature have in these changes.

Samples for our study were collected in 2005 and 2006 in a given quadrate of $100 \mathrm{~m}^{2}$ in a dry oak forest near Törökbálint, Hungary $\left(47^{\circ} 25^{\prime} 38^{\prime \prime} \mathrm{N}, 18^{\circ} 54^{\prime} 16^{\prime \prime} \mathrm{E}\right)$. In the sampling quadrate the most common tree species is turkey oak (Quercus cerris), common trees are field maple (Acer campestre), common ash (Fraxinus excelsior) and wild service tree (Sorbus torminalis). The most important herbaceous plants are broad-leafed Solomon's seal (Polygonatum latifolium) and garlic mustard (Alliaria petiolata). Samples were collected every two weeks from 15th March till $1^{\text {st }}$ December 2005 and from 26 ${ }^{\text {th }}$ March till 30th July 2006. Every time samples were collected randomly from three types of substrate within the quadrate: from $500 \mathrm{~cm}^{3}$ leaf litter, $300 \mathrm{~cm}^{3}$ foerna (from under the leaf litter) and $0.5 \mathrm{dm}^{2}$ hypnum moss (Hypnum cupressiforme) living on tree trunks. So we obtained altogether 19 moss samples and 18 leaf litter and 18 foerna samples in 2005 (the first time no leaf litter and foerna samples were collected); in 2006 we collected 10 leaf litter, 10 moss and 9 foerna samples (the tenth sample could not be analyzed for technical reasons). Components of the mesofauna were extracted with the help of a modified Berlese-Tullgren funnel (Coleman et al., 2004) and conserved in isopropyl alcohol, then they were sorted into larger groups, and finally oribatid mites were identified on genus level. For the identification the works of Balogh (1965), Balogh and Balogh (1992, 1972), Balogh and Mahunka (1980), Olsanowski (1996) and Hunt et al. (1998) were used.

The samples were analyzed based on oribatid mite communities with the help of multivariate computer aided methods using the software Syn-tax 2000 (Podani, 2001). The size difference between the samples from the three types of substrate was compensated by comparing the ratio and presence-absence data of the oribatid mite genera with the help of non-metric multidimensional scaling and classification method using several distances. Monte Carlo method was used to check these analyses. The means of the genus proportion of the substrate types were calculated, each mean was multiplied by a number created by a random generator twenty times, then these new values were divided by the sum of the random numbers. This way twenty data series were generated per substrate. These were compared using classification and ordination. Correspondence analysis and PCA analysis were used to identify the genera which are responsible for possible differentiations. The difference of the genera in specimen number and proportion was checked using MannWhitney test between the substrate types. The average diversity and the genus number were calculated in case of each substrate type.

In order to recognize seasonality patterns, each season was marked (in winter no sampling was conducted), and the changes in genus diversity and total abundance during a period of the study were displayed separately in case of the three substrate types. The relationship between the pattern changes of the communities and meteorological factors was analyzed with the help of data series from the meteorological station in Pestszentlörinc ( $47^{\circ} 25^{\prime} 53^{\prime \prime} \mathrm{N}$, 
$19^{\circ} 10^{\prime} 57^{\prime \prime}$ E). This station can be found 21 air km eastwards from our sampling point. In the case of precipitation the total precipitation amount of the sampling day and that of the preceding 5 and 10 days, and the standard deviation of the precipitation amount of the preceding 5, 10, 15, 20, 25 and 30 days were considered. In the case of temperature minimum and maximum values of the given days were available in our database, so in our analyses the means of these two values were considered. As for temperature data, the mean temperature of the sampling day and that of the preceding 5 and 10 days, and the standard deviation of temperature of the preceding 5, 10, 15, 20, 25 and 30 days were involved in our analyses. A redundancy analysis was conducted for all substrates first and then separately. In order to make the relationships more exact, the correlation between certain genera and meteorological factors was studied based on Spearman's analysis.

Seasonal changes could not be detected in the communities of the three substrates. In Fig. 2 change in the Shannon diversity of the genera in the case of the three substrates, however, a seasonal pattern recurring the following year cannot be detected.

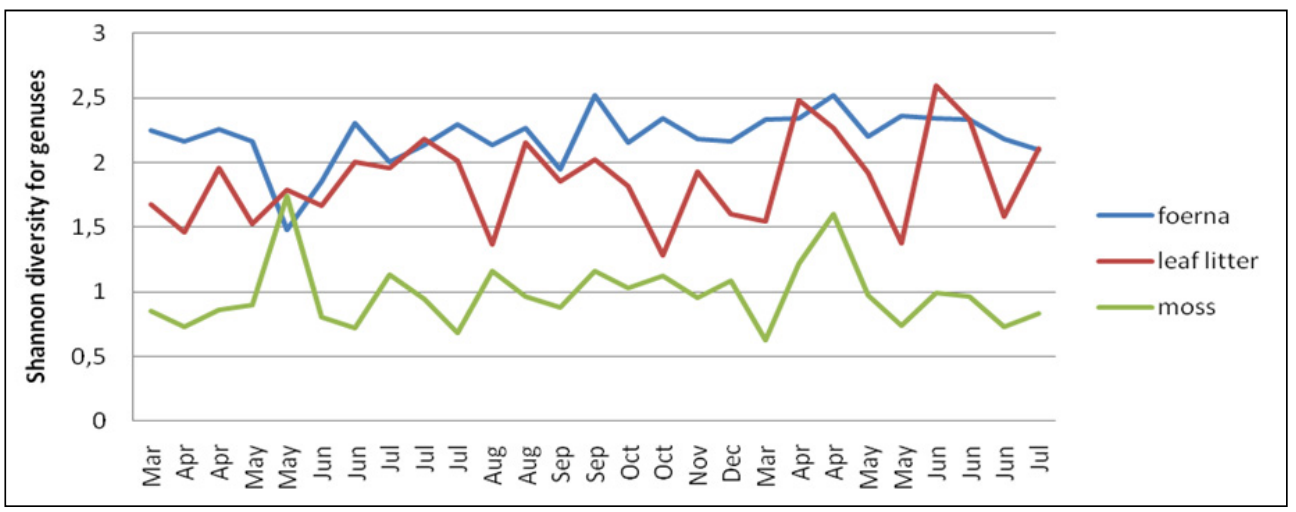

Figure 2. Change in the Shannon diversity of the genera in the case of the three substrates (2005-2006)

There is no relationships between the annual changes in precipitation amount and temperature and the composition and structure of Oribatid mite communities in leaf litter and foerna, however, in the case of moss there is. This can be caused by the genus Tectocepheus, which is one of the most frequent genera in moss samples (43\% of the adult specimens on average), and its correlation is $r=0.38$ regarding the five-day mean temperature (Spearman's correlation; $\mathrm{p}=0.043$ ); and regarding the ten-day mean temperature its correlation is $\mathrm{r}=0.45$ (Spearman's correlation; $\mathrm{p}=0.014$ ).

According to the research in seasonality during one and a half year we conclude that if any change occurs in the community during the year, it is not seasonal, i.e. neither genus-level diversity, nor abundance, nor the structure of the community have a recurring pattern in leaf litter, foerna and moss microhabitats. These results correspond with several previous data from the literature. Irmler $(2004,2006)$ observed oribatid mite communities in two 
different habitats over several years and he did not find any seasonal regularity either, except for some species. Those who interpreted their results in a way that seasonal change was found in oribatid mite communities drew a conclusion based on only one studied year or on the difference between two sampling months (Schenker, 1984; Stamou and Sgardelis, 1989; Askidis and Stamou, 1991; Clapperton et al., 2002). Such a hypothesis was, among others that important changes may occur between two temperate seasons in oribatid mite communities (Stamou and Sgardelis, 1989; Askidis and Stamou, 1991; Clapperton et al., 2002).(kétszer ugyanazok?) Although some of these studies were conducted in other types of habitats, i.e. not in temperate deciduous forests, a study covering a shorter period than a year is considered to be insufficient in the case of all habitats when observing regularities in seasonality. Schenker (1984) carried out a one year study around a turkey oak (Quercus cerris), a beech (Fagus sylvatica) and a Scots pine (Pinus sylvestris) in a moist deciduous forest in Switzerland. He found that annual change in abundance can be observed mostly around the beech and the pine, whereas it can hardly be observed around the oak, and species composition is not affected by seasonality, either. Oribatid mites occurred approximately in the same abundance further away from the oak trunks, than in the soil around it. For our study, data were collected in an oak forest. This may be the reason for the fact that we have not found any seasonal changes or changes in the genus composition, either. However, since Irmler (2006) conducted his studies in a beech forest and could not observe any seasonality either, and Schenker (1984) collected samples for only one year, it cannot be stated that the lack of seasonality is characteristic of oak forests.

If changes in communities do not occur seasonally, this can be brought into connection with micro- and macroclimatic effects. According to the results of Stamou and Sgardelis (1989) it could be concluded that the density of oribatid mites is largely influenced by temperature, although several later studies showed that temperature does not have the power to shape communities (Haimi et al., 2005). Irmler (2006) found that the structure of the community was in connection with the annual mean temperature only, and only some species showed significant correlation with some climatic factors. Webb et al. (1998) showed in the case of oribatid mite species living in polar areas that these species do not depend on seasonal changes, life cycle of the studied oribatid mite species is mainly influenced by temperature fluctuation. In our study proportional change correlating with temperature could be observed in the case of the genus Tectocepheus only and only in moss, however, no such connection can be found in the study of Irmler (2006), for example. Based on our results just like based on those of Irmler (2006) - it can be concluded that the structure of oribatid mite communities is not affected by climatic factors in leaf litter and foerna substrates. In moss samples the connection with temperature was due to the genus Tectocepheus.

Seasonality can also be observed in the decomposition of plant material. Quantity and quality of the decomposing plant material change seasonally in the leaf litter and in the soil so it can be assumed that oribatid mite communities may change correspondingly during the year. However, the exact role of oribatid mites in the decomposition of the leaf litter is not completely clear till this day (Lindo and Winchster, 2007). The most important role of 
oribatid mites in the decomposition is the spreading of microbiota as they feed mainly on fungi and bacteria, and they are not in direct connection with the leaf litter input, accordingly (Maraun et al., 2001). This corresponds with the phenomenon observed by us, that the quantity of leaf litter may not have influenced the compositional changes of the communities.

Our result that leaf litter and foerna substrates differ from moss was not interpreted by other literature yet, however, there are observations regarding other types of substrates. A common result is for example that the oribatid mite community living in the foliage of the trees differs significantly from the one living in the soil under the trees (e.g. Yoshida and Hijji, 2005; Karasawa and Hijii, 2008). Karasawa and Hijii (2004) showed that the substrate of oribatid mite communities living in the soil, in the foliage, on the bark of the tree trunks and on the remnants of algae accumulating on soil significantly differ from each other in seaside forests. In our study the community living in hypnum moss was simpler than the one living in the soil in the forest. Communities of moss and lichen are always relatively simple (Gjelstrup, 1979; Gjelstrup and Søchtig, 1979; Smrz, 1992; Smrz and Kocourková, 1999; Smrz, 2006). The three frequent genera found in moss turned up in the observations of others as well. Zygoribatula exilis is assumed to be a species living in moss (Gjelstrup, 1979), however, the Zygoribatula species found by us could be found on the forest ground as well. The genus Tectocepheus occurs everywhere from drier and more disturbed habitats to intact forests, accordingly it can also be found in moss in great quantities, especially because climatic fluctuation is larger in moss, what only some species can tolerate (Gjelstrup, 1979). A common epiphyte is Eremaeus oblongus (Smrz and Kocourková, 1999), in our study the genus Eremaeus could be found only in moss (except for only one foerna sample).

Therefore research showed that oribatid mite communities living in soil, leaf litter and hypnum moss, in Hungarian oak forests - similarly to those living in German beech forests - did not show seasonal changes. This result is important on the one hand because according to this, we are not bound to a season regarding sampling. However, besides that it would be important to detect the cause of the still occurring changes and patterns exactly. Furthermore it is unclear as well whether non-woody biocoenoses in the temperate zone or oribatid mite communities living in other climatic zones show seasonal changes.

Communities living in the soil differ from the oribatid mite community of moss living on tree trunks more significantly than from the community of the leaf litter. Oribatid mites in moss, especially the genus Tectocepheus, may be influenced by climatic factors to a large degree. In future it would be necessary to study oribatid mite communities of various microhabitats in order to detect exactly by which factors and to what degree their composition, changes and patterns are affected.

\section{Spatial similarity pattern of oribatid mite communities (case study)}

Oribatid mites of the tropical regions had been almost completely unknown for science before 1958. With the general use of the Berlese-funnel, systematic collections started at that time, which resulted in the collection of hundreds or thousands of species. However, the majority of 
these samples are unprocessed till these days. Professor J. Balogh and his fellow-workers had to realize, that the description of all the species living there is an impossible task.

And even if the recognizable morphological kinds of the samples will be described with decades of monumental work by the practices of formal describing taxonomy and according to the rules of nomenclature, the biological and coenological information content of these would still remain hidden. However the material extracted with the Berlese-Tullgren device informs us not only about the presence and morphological diversity, but also about the species' abundance and dominance as well. Moreover it has become clear that this material together, as it was brought in front of us, contains a heap of such kind of information, which would be impossible to read from single species or from their constitutional characteristics. The samples collected this way are suitable for zoocoenological examinations. This observation led Humboldt to the recognition of „basic forms" (Grundformen) and later to the revelation of formations, which means the structure that can be found in plant associations without the exact knowledge of species. The emphasis here is on the "visibility" of the vegetation, because the recognition of biological communities began with the sight of the flora: vegetation is a "landscape element". Animal communities - apart from some exceptions - live hidden in the vegetation. But the Berlese-device concentrates and makes them visible.

In this present section of our examinations, the objective is to clarify the methodological possibilities of biological indication and the information content of the coenological data matrices by an appropriately chosen indication case study. We also set the aim to apply univariate indicators and to exploit the possibilities of multivariate coenological pattern analysis.

In this study series, there is need to introduce the main Oribatid sinusia of tropical areas as per climatic, vegetation and elevation zones. According to the holistic approach, we start from the whole and proceed towards the smaller parts. As a first step, we examined the similarities between the Oribatid sinusia of the Neotropical Region and the Notogaea. Stemming from the fact that the vertical stratification of Oribatid fauna follows the vegetation zones, and took samples for examination from 3 elevation zones:

1. tropical rainforest

2. mossforest

3. paramo

In the study, we disregarded the mountain forest zone, which can be found between the zones of tropical rainforest and mossforest, because the determination of its borders is quite uncertain. To avoid transitions, Berlese-samples of tropical rainforest have been selected from $200 \mathrm{~m}$ elevation above sea level, close to the forest border. 2 ideal transects were set for representative sampling. The first one crosses Andes at Costa Rica, at the 10. degree of latitude, from coast to coast. The second one starts from Papua New-Guinea, from the valley of Fly River at the 4. degree of Southern latitude, and goes up to the $4000 \mathrm{~m}$ high ridge of $\mathrm{Mt}$ Wilhelm. As an amendment, samples were also taken near to the 23. degree of Southern 
latitude in an additional transect, crossing Serra do Mar and Serra do Mantiguera. This transect has been set because 200-300 years ago there's been a belt of dense tropical rainforest - which even exceeded Amazonia in biodiversity - in the most densely populated area of Brazil, along the line marked by Sao Paulo and Rio de Janeiro. Almost $95 \%$ of these forests have been devastated, but it could have been hoped that the rainforest spots reserved the original soil fauna - at least partially. 82 representative samples have been collected on 9 spots of the three transects. The spatial distribution of these samples and the abbreviation of individual sites can be seen in the next table:

$\begin{array}{lllll} & \text { Tropical rainforest } & \text { Mossforest } & \text { Paramo } & \\ \text { Costa Rica } & \text { RC: } 10 & \text { MC: } 10 & \text { PC: } 10 & 30 \\ \text { Brazil } & \text { RB: } 7 & \text { MB: } 6 & \text { PB: } 10 & 23 \\ \text { New-Guinea } & \text { RN: } 10 & \text { MN: } 9 & \text { PN: } 10 & 29 \\ & 27 & 25 & 30 & 82\end{array}$

Table 2.

The base table for our analyses was the 82 individual soil samples from the 9 examined habitat ( 3 habitat types of 3 areas) containing 111 Oribatid genera. For the various analyses, we created task-oriented assemblies from this base table.

Based on all of the individual samples, paired all samples with all other samples we created the similarity matrix of our data using multiple distance functions. In this current publication, Euclidean distance have been used.

Coenological similarity patterns can be analysed on multiple spatial scales (scale levels). We also analysed the similarity patterns of generic lists of different sites by NMDS with Euclidean distance, and hierarchical cluster-analysis. The two analytical results are shown projected onto each other (Figure 3). The multivariate similarity pattern of habitats' Oribatid community gave the expected picture. It can be stated that differences originating from the habitats and continents can also be recognized in the similarity patterns of the generic lists of the examined habitats. However, it can seem surprising that despite the vast geographical distances the pattern generating role of habitats does not disappear, it seems perhaps even more important. In accordance with the real ecological conditions, mossforest plays a transitional role between rainforest and paramo. However, mossforests are the most similar to each other and they are positioned in the middle of the similarity pattern, while the rest of the sites are separated radially. It is clearly visible that Brazilian sites are much more similar to each other than the Costa-Ricans.

Comparison of the sites can be fine-tuned if we also examine the similarity pattern of the individual soil samples considering every sample as different objects independent from the sites. We analysed this similarity pattern also by applying NMDS and Euclidean distance (Figure 4). Analysing the collective similarity pattern of every individual sample it can be stated that the groupings of elementary samples reflect their relations to the sites. This justifies the methodological decision by which sites are considered the basic objects of the examination. It can be stated furthermore, that habitat-type is unambiguously more 
significant pattern-generating factor than geographical attribution. Rainforests, mossforests and paramos lying thousands of kilometers from each other are more similar than sites of other habitats at only a few kilometers distance. Following the results of these pattern analyses, exact examination of the observed phenomena with a regression model seems to be practical.

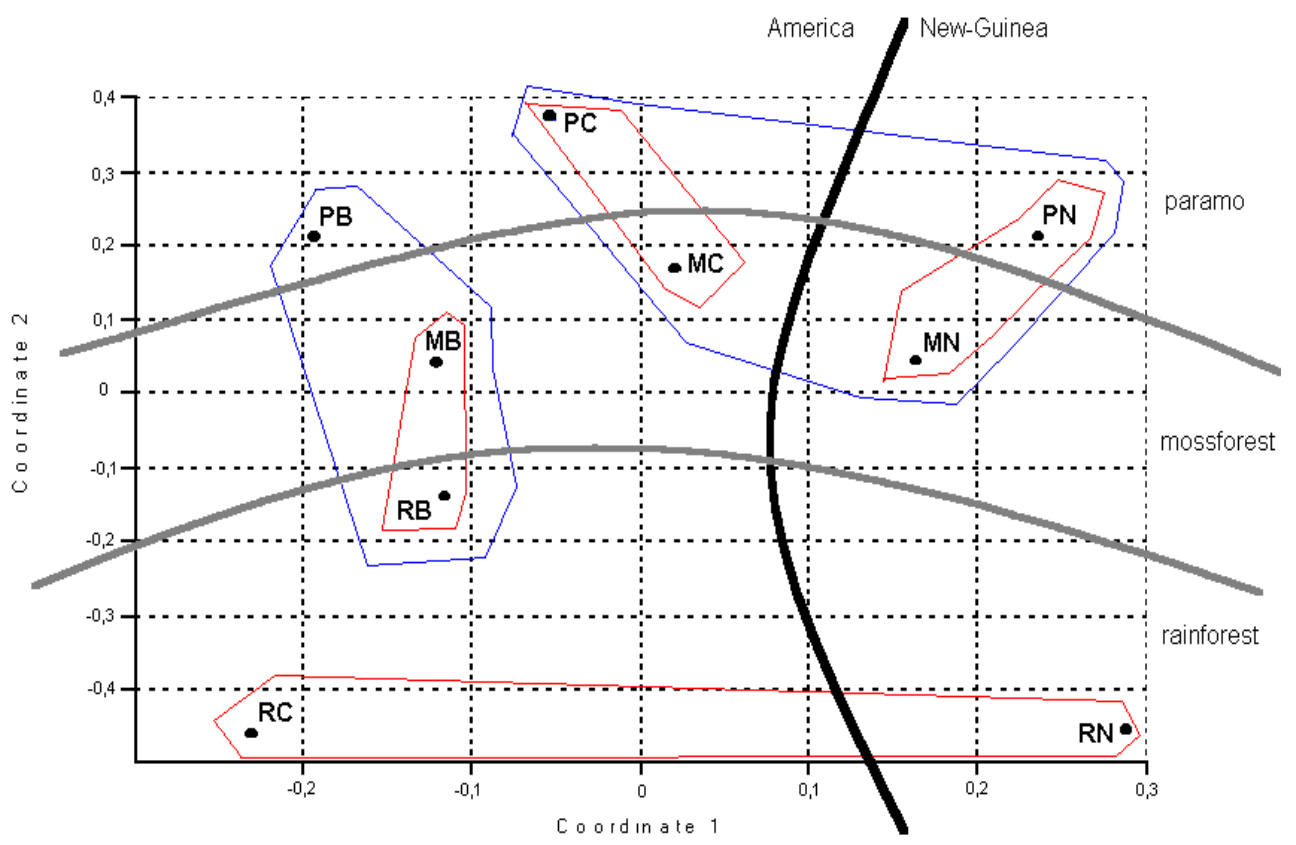

Figure 3. Similarity pattern of the examined sites in an NMDS ordination with the projection of the hierarchical cluster analysis results, applying Euclidean distance.

We pointed out that dissimilarities of habitats caused even by their type and also by the continent they originate from can be recognized in the similarity pattern of genus lists of the examined habitats. But if we analyze the overall similarity pattern of all the individual samples, it is quite conspicuous that the type of habitat is a much more significant patterngenerating factor than the geographical location. Rainforest, mossforests and paramos located many thousand kilometers from each other are more similar to each other than sites of other kind of habitats in only a few kilometers away.

The most important result of our case study is that the list of Oribatid genera as a coenological indicator, primarily characterizes the present ecological effects of the habitat and its climatically determined type of vegetation; and represents the effect of zoocoenological past in a much lesser extent. Thus, it can be concluded that a meritable scientific faunagenetical analysis should not be based upon geohistorical, but climatological grounds. This is why the ecological indication based on Oribatid genus lists provides unique possibilities for the purpose of climate change research. 


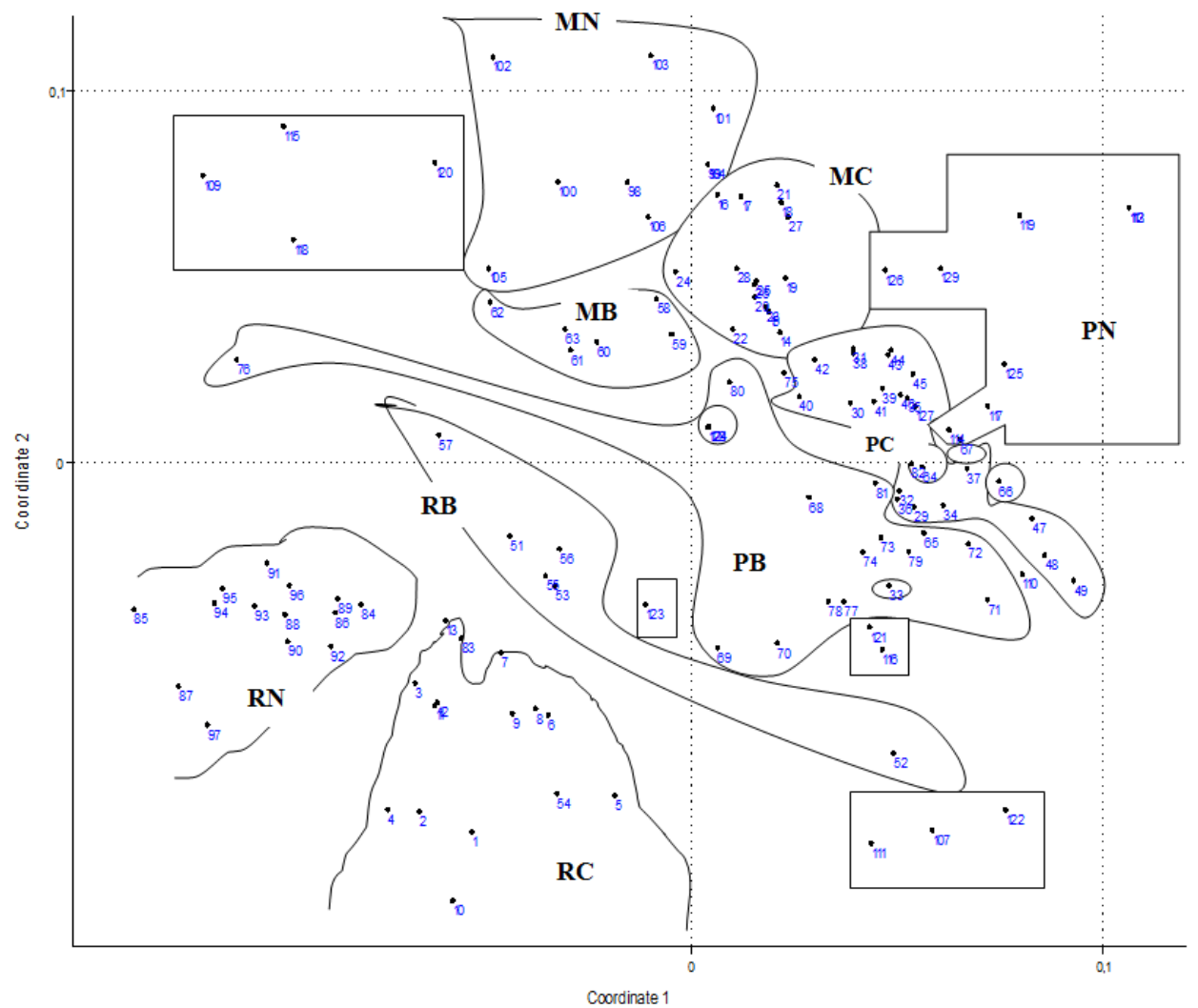

Figure 4. Similarity pattern of elementary samples in an NMDS ordination by applying Euclidean distance.

It became obvious that if we had chosen species and not genera as the basis of our examination, we would not get results that were interpretable from bioindicational aspect. This is because the majority of the described species would have appeared only as local specifica, and they do not provide any meritable information on similarity patterns - unless we are thinking in a very small grade of space. Species-level indication studies would be only rational in the case if we would deal only with cosmopolite species, but their number and detectability would not be sufficient for the majority of examinations for practical tasks. Thus, our important conclusion is that under current circumstances, the recommended taxonomical unit for indicational ecological studies can only be the genus. This statement is also important because many authors (primarily species describing taxonomists) consider a serious problem of indicational research that a number of researchers classify individuals only to genus level (Gulvik 2007). However, based on the work of Caruso (2006), we know that human contamination, intervention and disturbance can be better detected if we examine larger taxonomical units. It is also clear that rapid changes can not be detected on species-, but on community level. From the same work, it is also known that the species data 
of Oribatid mites can be raised to genus- or family level, and this does not cause loss of data or sensitivity by multivariate methods. According to Osler (1999), it is possible that habitat preference is determined rather at family level. Furthermore it is also known that there is strong relation between species-level and higher taxon level diversity indicators.

At the same time, the standardization and quantification of current Oribatid-collection methods would be obviously necessary for the development of the bioindicational methodology in order to make the data from different authors comparable. The need for this is emphasized more and more in literature (Gulvik 2007). A criteria-system of classifying the collected individuals into genera (or into other optional morphological groups) can be considered as a part of the standardized method. The current identificational and taxonomical practice in oribatodology is almost completely unsuitable for the purposes of biological indication research. Till such methods are unavailable, case studies can be conducted only if the person doing field sample collection and taxonomical processing is identical, and furthermore, this is only true if the coenological matrices have been created with the greatest care.

During our examinations (Balogh et al 2008), we pointed out that by advancing vertically upwards in the tropical high mountains (from rainforests towards the paramo vegetation), the average species number of genera present, and the extent of Holarctic and/or Antarctic relations of present genera grow, which can be well interpreted with the conception system of geographical analogy based on climatic similarities. This indication adequately supports former studies on the role of vegetational similarities and on genera as taxonomical units suitable for indication. Many authors (Andrew 2003, Melamud 2007 state that advancing upwards on the mountains, elevation above sea level and exposure have significant influence on the diversity of Oribatids. Besides, it is known that Oribatid diversity grows from the Boreal region towards warmer climates, but it does not grow further towards the tropics (Maraun 2007).

Furthermore, we pointed out that from the aspect of similarity of individual samples, among the examined habitat types the mossforest is the most homogeneous habitat, and paramo is the most heterogeneous. This latter phenomenon can be well interpreted if we consider the uniform moss cover prevalent in the mossforest, and the role of stable microclimate created by the moss cover. In the paramo, the observed proportion of species with low constancy level and also the heterogeneity of habitats (tussocks with different size) are high, and the role of the resulting microclimatic variability is obvious.

\section{Conclusions}

The genus lists of oribatid mites provide a unique indication device for the research of climate change, based on their following characteristics:

- Provide uncomparably simple, fast and effective sample collection opportunity in case of nearly any substrate type of nearly any habitat, all over the world. 
- $\quad$ Are easy and quick to indentify on a genus- level

- Have well processed, synthetised scientific literature

- Seasonal stability

- Reflect the intrinsic, fundamental ecological characteristics of their biotops, which reflection overwrites the zoogeographical patterns

- Extremely high information content of the distance functions of genus lists.

Category orders as results of the analyses mostly met our expectations, first of all in case of genus lists, i.e. larger distances between genus lists correspond to larger spatial scales. However, time difference within a year could not be pointed out to a considerable extent either on genus or on family level. The most important differences in the orders are the followings:

1. the difference between samples originating from the same and different types of substrate;

2. the difference between the distance of lists coming from the same type of substrate in a given site and the distance of genus lists originating from the same topographicum but from different or the same types of site;

3. the difference between the distance of lists coming from the same or different types of substrate in a given site and the distance of lists originating from different topographicums;

4. the difference between the distance of lists coming from the same types of sites in a given topographicum and the distance of lists originating from different topographicums.

The analysis on family level differs from that of genus level that family lists of the zoogeographic kingdoms resemble each other as much as family lists originating from the same types of substrate.

Thus, compiled a reference list with the help of which it can be expressed to what spatial distances the similarity - shown with distance functions - of the genus or family lists of two oribatid mite communities originating from samples of unknown quality corresponds. Disturbed and transformed habitats can be compared with the help of oribatid mite communities based on an existing reference list.

\section{Author details}

\section{Gergócs}

Department of Plant Taxonomy, Ecology and Theoretical Biology, Eötvös Loránd University, Faculty of Science, Budapest, Hungary

\section{R. Homoródi*}

Department of Mathematics and Informatics, Corvinus University of Budapest, Faculty of Horticulture, Budapest, Hungary

"Corresponding Author 
L. Hufnagel

Department of Mathematics and Informatics, Corvinus University of Budapest, Faculty of Horticulture, Budapest, Hungary

"Adaptation to Climate Change" Research Group of the Hungarian Academy of Sciences, Budapest, Hungary

\section{Acknowledgement}

We have to thank Prof. János Podani for his kind methodological help, Dr. Péter Balogh for his valuable professional help with the research of oribatid mites and for making the manuscripts from the Balogh-legacy available. We thank the "Adaptation to Climate Change" Research Group of the Hungarian Academy of Sciences and particularly the late Zsolt Harnos, who ensured the professional prerequisites of the research. Our research was supported by the Research Assistant Fellowship Support (Corvinus University of Budapest), "ALÖKI" Applied Ecological Research and Forensic Institute Ltd., the Landscape Architecture and Landscape Ecology PhD School of the Corvinus University of Budapest and the "Bolyai János" Research Fellowship (Hungarian Academy of Sciences, Council of Doctors). This work was supported by the research project of the National Development Agency TÁMOP 4.2.1.B-09/1/KMR-2010-0005.

\section{References}

[1] Altesor, A., Pineiro, G., Lezama, F., Jackson, R.B., Sarasola, M., Paruelo, J.M. (2006) Ecosystem changes associated with grazing in subhumid South American grasslands. Journal of Vegetation Science 17:323-332.

[2] Andres, P. (1999) Ecological risks of the use of sewage sludge as fertilizer in soil restoration effects on the soil microarthropod populations. - Land Degradation \& Development 10 (1): 67-77.

[3] Andres, P. (1999) Ecological risks of the use of sewage sludge as fertilizer in soil restoration effects on the soil microarthropod populations. Land Degradation \& Development 10 1:67-77.

[4] Andrew, N.R., Rodgerson, L., Dunlop, M. (2003) Variation in invertebrate-bryophyte community structure at different spatial scales along altitudinal gradients. - Journal of Biogeography 30 (5): 731-746.

[5] Arroyo, J., Iturrondobeitia, J.C. (2006) Differences in the diversity of oribatid mite communities in forests and agrosystems lands. - European Journal of Soil Biology 42: 259-269.

[6] Askidis, M.D., Stamou, G.P. (1991) Spatial and temporal patterns of an oribatid mite community in an evergreen-sclerophyllous formation (Hortiatis, Greece). Pedobiologia 35: 53-63.

[7] Badejo, M.A., Akinwole, P.O. (2006) Microenvironmental preferences of oribatid mite species on the floor of a tropical rainforest. - Experimental and Applied Acarology 40: 145-156. 
[8] Badejo, M.A., Espindola, J.A.A., Guerra, J.G.M., De Aquino, A.M., Correa, M.E.F. (2002) Soil oribatid mite communities under three species of legumes in an ultisol in Brazil. Experimental and Applied Acarology 27(4): 283-296.

[9] Balogh, J. (1965) A synopsis of the World Oribatid (Acari) Genera. - Acta Zoologica Academiae Scientiarum Hungaricae 9(1-2): 5-99.

[10] Balogh, J. (1972) The Oribatid Genera of the World. - Akadémiai Kiadó, Budapest.

[11] Balogh, J., Balogh, P. (1992) The Oribatid Mites Genera of the World. - The Hungarian National Museum Press, Budapest.

[12] Balogh, J., Mahunka, S. (1980) Atkák XV - Acari XV. - Magyarország Állatvilága, Fauna Hungariae, XVIII.(19).

[13] Balogh, J., Mahunka, S. (1983) Primitive Oribatids of the Palaearctic Region. Akadémiai Kiadó, Budapest.

[14] Balogh, P., Gergócs, V., Farkas , E., Farkas, P., Kocsis, M., Hufnagel, L. (2008) Oribatid assemblies of tropical high mountains on some points of the "Gondwana-bridge" - a case study. - Applied Ecology and Environmental Research 6(3) 127-158.

[15] Bargagli, R. (1998) Trace Elements in Terrestrial Plants - Springer and Landes Company, Berlin.

[16] Battigelli, J.P., Spence, J.R., Langor, D.W., Berch, S.M. (2004) Short-term impact of forest soil compaction and organic matter removal on soil mesofauna density and oribatid mite diversity. - Canadian Journal of Forest Research-Revue Canadienne de Recherche Forestiere 34(5) 1136-1149.

[17] Bedano, J.C., Cantu, M.P., Doucet, M.E. (2005) Abundance of soil mites (Arachnida : Acari) in a natural soil of central Argentina. - Zoological Studies 44(4) 505-512.

[18] Behan-Pelletier, V., Winchester, N. (1998) Arboreal oribatid mite diversity: Colonizing the canopy. - Applied Soil Ecology 9: 45-51.

[19] Behan-Pelletier, V.M. (1999) Oribatid mite biodiversity in agroecosystems: role for bioindication. - Agriculture, Ecosystems and Environment 74(1-3) 411-423.

[20] Behan-Pelletier, V.M. (1999) Oribatid mite biodiversity in agroecosystems: role for bioindication. - Agriculture, Ecosystems and Environment 74: 411-423.

[21] Bengtsson, G., Tranvik, L. (1989) Critical metal concentrations for forest soil invertebrates. - Water, Air and Soil Pollution 47: 381-417.

[22] Berch, S.M., Battigelli, J.P., Hope, G.D. (2007) Responses of soil mesofauna communities and oribatid mite species to site preparation treatments in high-elevation cutblocks in southern British Columbia. - Pedobiologia 51(1) 23-32.

[23] Berch, SM; Battigelli, JP; Hope, GD. 2007. Responses of soil mesofauna communities and oribatid mite species to site preparation treatments in high-elevation cutblocks in southern British Columbia. Pedobiologia, 51:23 - 32

[24] Berg, N.W., Pawluk, S. (1984) Soil mesofauna studies under different vegetative regimes in north central Alberta. - Can. J. Soil Sci. 64: 209-223.

[25] Berthelsen, B., Olsen, R., Steinnes, E. (1995) Ectomycorrhizal heavy metal accumulation as a contributing factor to heavy metal levels in organic surface soils. - The Science of the Total Environment 170: 141-149. 
[26] Black, H.I.J., Parekh, N.R., Chaplow, J.S., Monson, F., Watkins, J., Creamer, R., Potter, E.D., Poskitt, J.M., Rowland, P., Ainsworth, G., Hornung, M. (2003) Assessing soil biodiversity across Great Britain: national trends in the occurrence of heterotrophic bacteria and invertebrates in soil. - Journal of Environmental Management 67(3) 255266.

[27] Bolger, T., Curry, J.P. (1984) Influences of pig slurry on soil microarthropods in grasslands. Rev. - Écol. Biol. Sol 21: 269-281.

[28] Caruso T, Migliorini M (2006a) Micro-arthropod communities under human disturbance: is taxonomic aggregation a valuable tool for detecting multivariate change? Evidence from Mediterranean soil oribatid coenoses. Acta Oecol 30:46-53

[29] Caruso T, Migliorini M (2006b) A new formulation of the geometric series with applications to oribatid (Acari, Oribatida) species assemblages from human-disturbed mediterranean areas. Ecol Mod 95:402-406

[30] Caruso, T., Migliorini, M. (2006) Micro-arthropod communities under human disturbance: is taxonomic aggregation a valuable tool for detecting multivariate change? Evidence from Mediterranean soil oribatid coenoses. - Acta Eocologica 30(1) 46-53.

[31] Cepeda-Pizarro, J.G., Gutierrez, J.R., Valderrama, L., Vasquez, H. (1996) Phenology of the edaphic microarthropods in a Chilean coastal desert site and their response to water and nutrient amendments to the soil. - Pedobiologia 40(4) 352-363.

[32] Clapperton, M.J., Kanashiro, D.A., Behan-Pelletier, V.M. (2002) Changes in abundance and diversity of microarthropods associated with Fescue Prairie grazing regimes. Pedobiologia, 46(5) 496-511.

[33] Cole L., Buckland S.M., Bardgett R.G. (2008) Influence of disturbance and nitrogen addition on plant and soil animal diversity in grassland. - Soil Biology \& Biochemistry 40(2) 505-514.

[34]Coleman, D., Fu, S., Hendrix, P., Crossley Jr., D. (2002) Soil foodwebs in agroecosystems: impacts of herbivory and tillage management. - Eur. J. Soil Biol. 38(1) 21-28.

[35] Coleman, D.C. (2008) From peds to paradoxes: Linkages between soil biota and their influences on ecological processes. - Soil Biology \& Biochemistry 40(2) 271-289.

[36] Coleman, D.C., Crossley, Jr. D.A., Hendrix, P.F. (2004) Fundamentals of Soil Ecology. Chapter 9: Laboratory and Field Axercises in Soil Ecology. - Elsevier Academic Press, Burlington.

[37] Cortet, J., Gomot-De Vauflery, A., Poinsot-Balaguer, N., Gomot, L., Texier, C., Cluzeau, D. (1999) The use of invertebrate soil fauna in monitoring pollutant effects. - Eur. J. Soil Biol. 35(3) 115-134.

[38] Coulson, S.J., Hodkinson, I.D., Webb, N.R., Block, W., Bale, J.S., Strathdee, A.T., Worland, M.R., Wooley, C. (1996) Effects of experimental temperature elevation on high-arctic soil microarthropod populations. - Polar Biology 16(2) 147-153.

[39] Coulson, S.J., Leinaas, H.P., Ims, R.A., Sovik, G. (2000) Experimental manipulation of the winter surface ice layer: the effects on a High Arctic soil microarthropod community. - Ecography 23(3) 299-306. 
[40] Coulson, SJ; Leinaas, HP; Ims, RA; Sovik, G. Experimental manipulation of the winter surface ice layer: the effects on a High Arctic soil microarthropod community Ecography 23 3:299-306.

[41] Denneman, C.A.J., Van Straalen, N.M. (1991) The toxicity of lead and copper in reproduction tests using the oribatid mite Platynothrus peltifer. - Pedobiologia 35: 305311.

[42] Edwards, C.A., Lofty, J.R. (1975) The influence of cultivations on soil animal populations. - In: Vanek, J. (Ed.), Progress in Soil Zoology Academia Publishing House, Prague, pp. 399-406.

[43] Enami, Y., Shiraishi, H., Nakamura, Y. (1999) Use of soil animals as bioindicators of various kinds of soil management in northern Japan. - Jarq-Japan Agricultural Research Quarterly 33(2) 85-89.

[44] Erdmann, G., Floren, A., Linsenmair, K.E., Scheu, S., Maraun, M. (2006) Little effect of forest age on oribatid mites on the bark of trees. - Pedobiologia 50: 433-441.

[45] Fagan, L.L., Didham, R.K., Winchester, N., Behan-Pelletier, V., Clayton, M., Lindquist, E., Ring, R.A. (2006) An experimental assessment of biodiversity and species turnover in terrestrial vs. canopy leaf litter. - Eocologia 147: 335-347.

[46] Fox, C.A., Fonseca, E.J.A., Miller, J.J., Tomlin, A.D. (1999) The influence of row position and selected soil atributes on Acarina and Collembola in no-till and conventional continuous corn on a clay loam soil. - Appl. Soil Ecol. 13(1) 1-8.

[47] Franklin, E., Magnusson, W.E., Luizao, F.J. (2005) Relative effects of biotic and abiotic factors on the composition of soil invertebrate communities in an Amazonian savanna. - Applied Soil Ecology 29(3) 259-273.

[48] Franklin, E; Magnusson, WE; Luizao, FJ. 2005 Relative effects of biotic and abiotic factors on the composition of soil invertebrate communities in an Amazonian savanna Applied Soil Ecology 29 3:259 273

[49] Gackowski, G., Seniczak, S., Klimek, A., Zalewski, W. (1997) Soil mites (Acari) of young Scots pine forests in the region polluted by a copper smelting works at G1ogo'w (in Polish) - Zeszyty Naukowe ATR, Bydgoszcz, Ochrona S' rodowiska 208: 27-35.

[50] Gergócs, V., Garamvölcsi, Á., Homoródi, R., Hufnagel, L. (2011) Seasonal change of oribatid mite communities (Acari, Oribatida) in three different types of microhabitats in an oak forest. - Applied Ecology and Environmental Research

[51] Gergócs, V., Garamvölcsi, Á., Hufnagel, L. (2010) Indication strength of coenological similarity patterns based on genus-level taxon lists. - Applied Ecology and Environmental Research

[52] Gergócs, V., Hufnagel, L. (2009) Application of Oribatid Mites as Indicators. - Applied Ecology and Environmental Research 7(1) 79-98.

[53] Gill, R.W. (1969) Soil microarthropod abundance following old-field litter manipulation. - Ecology 50: 805-816.

[54] Gjelstrup, P. (1979) Epiphytic cryptostigmatic mites on some beechand birch-trees in Denmark. - Pedobiologia 19: 1-8.

[55] Gjelstrup, P., Søchting, U. (1979) Cryptostigmatic mites (Acarina) associated with Ramalina siliquosa (Lichenes) on Bornholm in the Baltic. - Pedobiologia 19: 237-245. 
[56] Gulvik, M.E. (2007) Mites (Acari) As Indicators of Soil Biodiversity and Land Use Monitoring: a Review. - Polish Journal of Ecology 55(3) 415-440.

[57] Hågvar, S. (1998) Mites (Acari) developing inside decomposing spruce needles: biology and effect on decomposition rate. - Pedobiologia 42: 358-377.

[58] Hågvar, S., Abrahamsen, G. (1990) Microarthropods and Enchytraeidae (Oligochaeta) in naturally lead-contaminated soils: a gradient study. - Environmental Entomology 19: 1263-1277.

[59] Haimi, J., Laamanen, J., Penttinen, R., Räty, M., Koponen, S., Kellomäki, S., Niemelä, P. (2005) Impacts of elevated $\mathrm{CO}_{2}$ and temperature on the soil fauna of boreal forests. Applied Soil Ecology 30(2) 104-112.

[60] Hammer, M. (1952) Investigation On The Microfauna Of Nothern Canada, Part I, Oribatidae. - Acta Arctica.

[61] Hammer, M. (1958) Investigation On The Oribatid Fauna Of The Andes Mountains, I. Argentine and Bolivia.

[62] Hammer, M. (1961) Investigations On The Oribatid Fauna Of The Andes Mountains, II. Peru.

[63] Hammer, M. (1962) Investigations On The Oribatid Fauna Of The Andes Mountains, III. Chile.

[64] Hammer, M. (1962) Investigations On The Oribatid Fauna Of The Andes Mountains, IV. Patagonia.

[65] Hammer, M. (1966) Investigations On The Oribatid Fauna Of New Zealand, Part I-III.

[66] Hammer, M. (1972) Investigations On The Oribatid Fauna Of Tahiti And On Some Oribatids Found On The Atoll Rangiroa.

[67] Hammer, M., Wallwork., J.A. (1979) A review of the world distribution of oribatid mites (Acari: Cryptostigmata) in relation to continental drift. - Biol. Skrift. 22: 1-31.

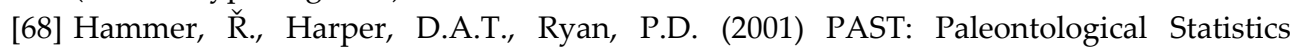
Software Package for Education and Data Analysis. - Palaeontologia Electronica 4(1) 9. http://palaeo-electronica.org/2001_1/past/issue1_01.htm

[69] Hodkinson, I.D., Coulson, S.J., Webb, N.R., Block, W. (1996) Can high Arctic soil microarthropods survive elevated summer temperatures? - Functional Ecology 10(3) 314-321.

[70] Hopkin, S.P., Watson, K., Martin, M.H., Mould, M.L. (1985) The assimilation of heavy metals by Lithobius variegatus and Glomeris marginata (Chilopoda, Diplopoda) Bijdragen tot de Dierkunde 55: 88-94.

[71] Hulsmann, A., Wolters, V., (1998) The effects of different tillage practices on soil mites, with particular reference to Oribatida. - Appl. Soil Ecol. 9: 327-332.

[72] Hunt, G.S., Colloff, M.J., Dallwitz, M.J, and Walter, D.E. (1998) Oribatid mites: an interactive key to Oribatid mites of Australia. CD-ROM for MS-Windows. - CSIRO Publishing, Melbourne.

[73] Hunt, G.S., Norton, R.A., Kelly, J.P.H., Collof, M.J., Lindsay, S.M., Dallwitz, M.J., Walter, D.E. (1998) Oribatid mites: an interactive glossary to oribatid mites. CD-ROM for MS-Windows. - CSIRO Publishing, Melbourne. 
[74] Irmler, U. (2004) Long-term fluctuation of the soil fauna (Collembola and Oribatida) at groundwater-near sites in an alder wood. - Pedobiologia 48(4) 349-363.

[75] Irmler, U. (2006) Climatic and litter fall effects on collembolan and oribatid mite species and communities in a beech wood based on a 7 years investigation. - European Journal of Soil Ecology 42(1) 51-62.

[76] Jing, S., Solhoy, T., Wang, H.F., Vollan, T.I., Xu, R.M. (2005) Differences in soil arthropod communities along a high altitude gradient at Shergyla Mountain, Tibet, China. - Arctic, Antarctic and Alpine Research 37(2) 261-266.

[77] Johnston, J.M., Crossley Jr. D.A. (2002) Forest ecosystem recovery in a southeast US: soil ecology as an essential component of ecosystem management. - Forest Ecology and Management 155(1-3) 187-203.

[78] Kaneko, N., Salamanca, E.F. (1999) Mixed leaf litter effects on decomposition rates and soil microarthropod communities in an oak-pine stand in Japan. - Ecological Research 14(2) 131-138.

[79] Kaneko, N., Sugawara, Y., Miyamoto, T., Hasegawa, M., Hiura, T. (2005) Oribatid mite community structure and tree species diversity: A link? - Pedobiologia 49(6) 521-528.

[80] Kaneko, N; Sugawara, Y; Miyamoto, T; Hasegawa, M; Hiura, T.2005 Oribatid mite community structure and tree species diversity: A link? Pedobiologia 49 6:521- 528.

[81] Karasawa, S., Hijii, N. (2004) Effects of microhabitat diversity and geographical isolation on oribatid mite (Acari: Oribatida) communities in mangrove forests. Pedobiologia, 48(3) 245-255.

[82] Karasawa, S., Hijii, N. (2008) Vertical stratification of oribatid (Acari: Oribatida) communities in relation to their morphological and life-history traits and tree structures in a subtropical forest in Japan. - Ecological Research 23(1) 57-69.

[83] Khan, A.G., Kuek, C., Chaudhry, T.M., Khoo, C.S., Hayes, W.J. (2000) Role of plants, mycorrhizae and phytochelators in heavy metal contaminated land remediation. Chemosphere 41(1-2) 197-207.

[84] Koehler, H., Born, H. (1989) The influence of vegetation structure on the development of soil mesofauna. - Agriculture Ecosystems and Environment 27(1-4) 253-269.

[85] Korentajer, L. (1999) A review of the agricultural use of sewage sludge: benefits and potential hazards. - Water Air Soil Pollut. 17: 189-196.

[86] Koukoura, Z., Mamolos, A.P., Kalburtji, K.L. (2003) Decomposition of dominant plant species litter in a semi-arid grassland. - Appl. Soil Ecol. 23(1) 13-23.

[87] Kovác, L., L'uptácik, P., Miklisová, D, Mati, R. (2001) Soil Oribatida and Collembola communities across a land depression in an arable field. - Eur. J. Soil Biol. 37: 285-289.

[88] Krogh, P.H., Pedersen, M.B. (1997) Ecological effects assessment of industrial sludge for microarthropods and decomposition in a spruce plantation. - Ecotoxicol. Environ 36(2) 162-168.

[89] Lebrun, Ph., van Straalen, N.M. (1995) Oribatid mites: prospects for their use in ecotoxicology. - Experimental \& Applied Acarology 19: 361-379.

[90] Liiri, M., Haimi, J., Setala, H. (2002) Community composition of soil microarthropods of acid forest soils as affected by wood ash application. - Pedobiologia 46(2) 108-124. 
[91] Lindberg, N., Bengtsson, J. (2005) Population responses of oribatid mites and collembolans after drought. - Applied Soil Ecology 28(2) 163-174.

[92] Lindberg, N., Bengtsson, J. (2006) Recovery of forest soil fauna diversity and composition after repeated summer droughts. - Oikos 114: 494-506.

[93] Lindberg, N., Engtsson, J.B., Persson, T. (2002) Effects of experimental irrigation and drought on the composition and diversity of soil fauna in a coniferous stand. - Journal of Applied Ecology 39(6) 924-936.

[94] Lindo, Z., Visser, S. (2004) Forest floor microarthropod abundance and oribatid mite (Acari: Oribatida) composition following partial and clear-cut harvesting in the mixedwood boreal forest. - Canadian Journal of Forest Research-Revue Canadienne de Recherche Forestiere 34(5) 998-1006.

[95] Lindo, Z., Winchester, N. (2006) A comparison of microarthropod assemblages with emphasis on oribatid mite in canopy suspended soils and forest floors associated with ancient western redcedar trees. - Pedobiologia 50: 31-41.

[96] Lindo, Z., Winchester, N. (2007) Oribatid mite communities and foliar litter decomposition in canopy suspended soils and forest floor habitats of western redcedar forests, Vancouver Island, Canada. - Soil Biology and Biochemistry 39(11) 2957-2966.

[97] Lindo, Z; Visser, S. 2004 Forest floor microarthropod abundance and oribatid mite (Acari : Oribatida) composition following partial and clear-cut harvesting in the mixedwood boreal forest Canadian Journal of Forest Research-Revue Canadienne De Recherche Forestiere. 34 5:998-1006.

[98] Luxton, M. (1981) Studies on the Oribatid mites of a Danish Beech wood soil IV. Developmental biology. - Pedobiologia 21: 312-340.

[99] Maraun, M., Alphei, J., Beste, Ph., Bonkowski, M., Buryn,R., Migge, S., Peter, M., Schaefer, M., Scheu, S. (2001) Indirect effects of carbon and nutrient amendments on the soil meso- and microfauna of a beechwood. - Biology and Fertility of Soils 34(4) 222229.

[100] Maraun, M., Salamon, J.A., Schneider, K., Schaefer, M., Scheu, S. (2003) Oribatid mite and collembolan diversity, density and community structure in a moder beech forest (Fagus sylvatica) effects of mechanical perturbations. - Soil Biology \& Biochemistry 35(10) 1387-1394.

[101] Maraun, M; Schatz, H; Scheu, S. 2007. Awesome or ordinary? Global diversity patterns of oribatid mites. ECOGRAPHY, 30:209 - 216- (benne van, de formátum??)

[102] Marra, J.L., Edmonds, R.L. (1998) Effects of coarse woody debris and soil depth on the density and diversity of soil invertebrates on clearcut and forested sites on the Olympic Peninsula, Washington. - Environ. Entomol. 27(5) 1111-1124.

[103] Melamud, V., Beharav, A., Pavlicek, T., Nevo, E. (2007) Biodiversity interslope divergence of Oribatid Mites at „Evolution Canyon”, Mount Carmel, Israel. - Acta Zoologica Academiae Scientiarum Hungaricae 53(4) 381-396.

[104] Migliorini, M., Bernini, F. (1999) Oribatid mite coenoses in the Nebrodi Mountains (Northern Sicily). - Pedobiologia 43(4) 372-383. 
[105] Migliorini, M., Fanciulli, P.P., Bernini, F., (2003) Comparative analysis of two edaphic zoocoenoses (Acari Oribatida, Hexapoda Collembola) in the area of Orio al Serio Airport (Bergamo, northern Italy). - Pedobiologia 47(1) 9-18.

[106] Migliorini, M., Petrioli, A., Bernini, F. (2002) Comparative analysis of two edaphic zoocoenoses (Oribatid mites and Carabid beetles) in five habitats of the 'Pietraporciana' and 'Lucciolabella' Nature Reserves (Orcia Valley, central Italy). - Acta Eocologica 23: 361-374.

[107] Migliorini, M., Pigino, G., Caruso, T., Fanciulli, P.P., Leonzio, C., Bernini, F. (2005) Soil communities (Acari Oribatida, Hexapoda Collembola) in a clay pigeon shooting range. - Pedobiologia 49(1) 1-13.

[108] Minor, M.A., Norton, R.A. (2004) Effects of soil amendments on assemblages of soil mites (Acari : Oribatida, Mesostigmata) in short-rotation willow plantings in central New York Canadian Journal of Forest Research-Revue (Canadienne de Recherche Forestiere) 34: 1417-1425.

[109] Mitchell, R.J., Campbell, C.D., Chapman, S.J., Osler, G.H.R., Vanbergen, A.J., Ross, L.C., Cameron, C.M., Cole, L. (2007) The cascading effects of birch on heather moorland: a test for the top-down control of an ecosystem engineer. - Journal of Ecology 95(3) 540554.

[110] Moldenke, A.R., Thies, W.G. (1996) Application of chloropicrin to control laminated root rot: Research design and seasonal dynamics of control populations of soil arthropods. - Environmental Entomology 25(5) 925-932.

[111] Moore, J.C., Snider, R.J., Robertson, L.S. (1984) Effects of different management practices on Collembola and Acarina in corn production systems. 1. The effects of notillage and Atrazine. - Pedobiologia, 26(2) 143-152.

[112] Müller, P. (1980) Arealsysteme und Biogeographie. - Ulmer, Stuttgart.

[113] Neave, P., Fox, C.A. (1998) Response of soil invertebrates to reduced tillage systems established on a clay loam soil. - Appl. Soil Ecol. 9(1-3) 423-428.

[114] Norton, R.A. (1994) Evolutionary aspects of oribatid mites life histories and consequences for the origin of the Astigmata. - In: M.A. Houck (Ed.), Mites: Ecological and Evolutionary Analyses of Life-History Patterns, Chapman \& Hall, New York, pp. 99-135.

[115] Norton, R.A., Behan-Pelletier, V.M. (1991) Calcium carbonate and calcium oxalate as cuticular hardening agents in oribatid mites (Acari: Oribatida). - Canadian Journal Of Zoology 69(6) 1504-1511.

[116] Norton, R.A., Kethley, J.B., Johnston, B.E., Oconnor, B.M. (1993) Phylogenetic perspectives on genetic systems and reproductive modes of mites. - In: Wrensch, D, and Ebbert, M. (eds) Evolution and diversity of sex ratio in insects and mites, Chapman and Hall.

[117] Noti, M.I., Andre, H.M., Ducarme, X., Lebrun, P. (2003) Diversity of soil oribatid mites (Acari : Oribatida) from High Katanga (Democratic Republic of Congo) a multiscale and multifactor approach - Biodiversity And Conservation 12(4) 767-785. 
[118] Noti, M.I., André, H.M., DufrSne. M. (1996) Soil oribatid mite communities (Acari: Oribatidaj from high Shaba (Zäire) in relation to vegetation. - Applied Soil Ecology, 5(1) 81-96.

[119] O'Lear, H.A., Blair, J.M. (1999) Responses of soil microarthropods to changes in soil wateravailability in tallgrass prairie. - Biology and Fertility of Soils 29(2) 207-217.

[120] Olejniczak, I. (2004) Communities of soil microarthropods with special reference to collembola in midfield shelterbelts. - Polish Journal of Ecology 52(2) 123-133.

[121] Olsanowski, Z. (1996) A monograph of the Nothridae and Camisiidae of Poland (Acari: Oribatida: Crotonoidea). - Genus International Journal of Invertebrate Taxonomy (Supplement), Wrocław.

[122] Osler, G.H.R., Beattie, A.J. (1999) Taxonomic and structural similarities in soil oribatid communities. - Ecography 22(5) 567-574.

[123] Osler, G.H.R., Cole, L., Keith, A.M. (2006) Changes in oribatid mite community structure associated with the succession from heather (Calluna vulgaris) moorland to birch (Betula pubescens) woodland. - Pedobiologia 50(4) 323-330.

[124] Osler, G.H.R., Harrison, L., Kanashiro, D.K., Clapperton, M.J. (2008) Soil microarthropod assemblages under different arable crop rotations in Alberta, Canada. Applied Soil Ecology, 38(1) 71-78.

[125] Osler, G.H.R., Korycinska, A., Cole, L. (2006) Differences in litter mass change mite assemblage structure on a deciduous forest floor. - Ecography 29: 811-818.

[126] Osler, G.H.R., Murphy, D.V. (2005) Oribatid mite species richness and soil organic matter fractions in agricultural and native vegetation soils in Western Australia. Applied Soil Ecology 29(1) 93-98.

[127] Osler, GHR; Beattie, AJ. 2001 Contribution of oribatid and mesostigmatid soil mites in ecologically based estimates of global species richness Austral Ecology 26 1:70-79.

[128] Podani, J. (1989) Comparison of ordinations and classifications of vegetation data. Vegetatio 83: 111-128.

[129] Podani, J. (1997) Bevezetés a többváltozós biológiai adatfeltárás rejtelmeibe. - Scientia Kiadó, Budapest.

[130] Podani, J. (2001) SYN-TAX 2000 user's manual. - Scientia Kiadó, Budapest.

[131] Prinzing A., Kretzler S., Badejo A., Beck L., 2002 Traits of oribatid mite species that tolerate habitat disturbance due to pesticide application, Soil Biology \& Biochemistry 34 1655-1661

[132] Prinzing A., Kretzler S., Badejo A., Beck L. (2002) Traits of oribatid mite species thattolerate habitat disturbance due to pesticide application. - Soil Biology \& Biochemistry 34(11) 1655-1661.

[133] Reynolds, B.C., Crossley, D.A., Hunter, M.D. (2003) Response of soil invertebrates to forest canopy inputs along a productivity gradient. - Pedobiologia 47(2) 127- 139.

[134] Salmon, S., Mantel, J., Frizzera, L., Zanella, A. (2006) Changes in humus forms and soil animal communities in two developmental phases of Norway spruce on an acidic substrate. - Forest Ecology and Management 237(1-3) 47-56. 
[135] Salmon, S; Mantel, J; Frizzera, L; Zanella, A. 2006. Changes in humus forms and soil animal communities in two developmental phases of Norway spruce on an acidic substrate. Forest Ecology and Management. 237: 47-56.

[136] Schenker, R. (1984) Spatial and seasonal distribution patterns of oribatid mites (Acari: Oribatei) in a forest soil ecosystem. - Pedobiologia 27(22) 133-149.

[137] Scheu, S., Schulz, E. (1996) Secondary succession, soil formation and development of a diverse community of oribatids and saprophagous soil macro-invertebrates. Biodiversity and Conservation 5(2) 235-250.

[138] Seastedt, T.R. (1984) The role of microarthropods in decomposition processes. Annual Review of Entomology 29: 25-46.

[139] Seniczak, S., Bukowski, G., Seniczak, A., Bukowska, H. (2006) Soil Oribatida (Acari) of ecotones between Scots pine forest and lakes in the National Park „Bory Tucholskie”. Biological Lett 43(2) 221-225.

[140] Seniczak, S., Dabrowski, J., Dlugosz, J. (1995) Effect Of Copper Smelting Air Pollution On The Mites (Acari) Associated With Young Scots Pine Forests Polluted By A CopperSmelting Works At Giogow, Poland. I. Arboreal Mites. - Water, Air, and Soil Pollution 94(3-4) 71-84.

[141] Siepel H, 1996, Biodiversity of soil microarthropods: The filtering of species Biodiversity and Conservation 5, 2: 251-260

[142] Siepel, H. (1995) Are some mites more ecologically exposed to pollution with lead than others? - Experimental and Applied Acarology 19(7) 391-398.

[143] Siepel, H. (1996) Biodiversity of soil microarthropods: The filtering of species. Biodiversity and Conservation 5(2) 251-260.

[144] Skubala, P., Gulvik, M. (2005) Pioneer Oribatid Mite Communities (Acari, Oribatida) in Newly Exposed Natural (Glacier Foreland) and Anthropogenic (Post-Industrial Dump) Habitats. - Polish Journal of Ecology 53(3) 395-407.

[145] Skubala, P., Kafel, A. (2004) Oribatid mite communities and metal bioaccumulation in oribatid species (Acari, Oribatida) along the heavy metal gradient in forest ecosystems. - Environmental Pollution 132(1) 51-60.

[146] Smrž, J. (1992) The ecology of the microarthropod community inhabiting the moss cover of roofs. - Pedobiologia 36(6) 331-340.

[147] Smrž, J. (2006) Microhabitat selection in the simple oribatid community dwelling in epilithic moss cover (Acari: Oribatida). - Naturwissenschaften 93(11) 570-576.

[148] Smrž, J., Kocourková, J. (1999) Mite communities of two epiphytic lichen species (Hypogymnia physodes and Parmelia sulcata) in the Czech Republic. - Pedobiologia 43: 385-390.

[149] Stamou G.P.; Asikidis M.D.; Argyropoulou M.D.; Iatrou G.D., 1995 Respiratory Responses of Oribatid Mites to Temperature Changes , Journal of Insect Physiology, 41 3:229-233(5)

[150] Stamou, G.P., Asikidis, M.D., Argyropoulou, M.D., Iatrou, G.D. (1995) Respiratory Responses of Oribatid Mites to Temperature Changes, Journal of Insect Physiology 41(3) 229-233(5). 
[151] Stamou, G.P., Sgardelis, S.P. (1989) Seasonal distribution patterns of oribatid mites (Acari: Cryptostigmata) in a forest ecosystem. - Journal of Animal Ecology 58(3) 893904.

[152] Steiner, W.A. (1995) Influence of air pollution on moss-dwelling animals: 3. Terrestrial fauna, with emphasis on Oribatida and Collembola. - Acarologia 36(2) 149-176.

[153] Straalen N.M., Butovsky R.O., Pokarzhevskii A.D., Zaitsev A.S., Verhoef S.C., 2001, Metal concentrations in soil and invertebrates in the vicinity of a metallurgical factory near Tula (Russia) Pedobiologia 45, 451-466

[154] Straalen, N.M., Butovsky, R.O., Pokarzhevskii, A.D., Zaitsev, A.S., Verhoef, S.C. (2001) Metal concentrations in soil and invertebrates in the vicinity of a metallurgical factory near Tula (Russia). -Pedobiologia 45(5) 451-466.

[155] Sulkava, P., Huhta, V. (2003) Effects of hard frost and freeze-thaw cycles on decomposer communities and $\mathrm{N}$ mineralisation in boreal forest soil. - Applied Soil Ecology 22(3) 225-239.

[156] Taylor, A.R., Schröter, D., Pflug, A., Wolters, V. (2002) Response of different decomposer communities to the manipulation of moisture availability: potential effects of changing precipitation patterns. - Global Change Biology 10(8) 1314-1324.

[157] Taylor, A.R., Wolters, V. (2005) Responses of oribatid mite communities to summer drought: The influence of litter type and quality. - Soil Biology \& Biochemistry 37(11) 2117-2130.

[158] Trueba, D.P., Gonzalez, M.M.V., Aragones, C.R. (1999) Soil mesofaunal communities from a periodically flooded lowland forest in the Si'an Kaan, Biosfere Reserve, Quintana Roo, Mexico. - Revista De Biologia Tropical 47(3) 489-492

[159] Tsiafouli, M.A., Kallimanis, A.S., Katana, E., Stamou, G.P., Sgardelis, S.P. (2005) Responses of soil microarthropods to experimental short-term manipulations of soil moisture - Applied Soil Ecology 29(1)17 26

[160] Uvarov, A.V. (2003) Effects of diurnal temperature fluctuations on population responses of forest floor mites. - Pedobiologia 47(4) 331-339.

[161] Valix, M., Tang, J.Y., Malik, R. (2001) Heavy metal tolerance of fungi. - Minerals Engineering 14(5) 499-505.

[162] Wallwork, J.A. (1983) Oribatids in forest ecosystems. - Annual Review of Entomology 28: 109-130.

[163] Walter, D.E., Proctor, H.C. (1999) Mites: Ecology, Evolution and Behaviour. - CABI Publishing, Wallingford. 322pp.

[164] Webb, N.R., Coulson, S.J., Hodkinson, I.D., Block, W., Bale, J.S., Strathdee, A.T. (1998) The effects of experimental temperature elevation on populations of cryptostigmatic mites in high Arctic soils. - Pedobiologia 42(4) 298-308.

[165] Yoshida, T., Hijii, N. (2005) The composition and abundance of microarthropod communities on arboreal litter in the canopy of Cryptomeria japonica trees. - Journal of Forest Research 10(1) 35-42.

[166] Zaitsev, A.S., Chauvat, M., Pflug, A., Wolters, V. (2002) Oribatid mite diversity and community dynamics in a spruce chronosequence. - Soil Biology \& Biochemistry 34(12) 1919-1927. 
[167] Zaitsev, A.S., van Straalen, N.M. (2001) Species diversity and metal accumulation in oribatid mites (Acari, Oribatida) of forests affected by a metallurgical plant. Pedobiologia 45(5) 467-479.

[168] Zaitsev, AS; van Straalen, NM. 2001 Species diversity and metal accumulation in oribatid mites (Acari, Oribatida) of forests affected by a metallurgical plant Pedobiologia 45 5:467-479. 